\title{
Evaluating kidney function using a point- of-care creatinine test in Ugandan children with severe malaria: a prospective cohort study
}

\author{
Anthony Batte ${ }^{1}$, Kristin J. Murphy², Ruth Namazzi ${ }^{3}$, Katrina Co${ }^{2}$, Robert O. Opoka ${ }^{3}$, John M. Ssenkusu4, \\ Chandy C. John ${ }^{2}$ and Andrea L. Conroy ${ }^{2 *}$ (1)
}

\begin{abstract}
Background: Acute kidney injury (AKI) disproportionately affects individuals in low-and middle-income countries (LMIC). However, LMIC - particularly countries in sub-Saharan Africa - are under-represented in global AKI research. A critical barrier in diagnosing AKI is access to reliable serum creatinine results. We evaluated the utility of a point-ofcare test to measure creatinine and diagnose AKI in Ugandan children with malaria.
\end{abstract}

Methods: Paired admission creatinine was assessed in 539 Ugandan children 6 months to 4 years of age hospitalized with severe malaria based on blood smear or rapid diagnostic test. Creatinine levels were measured using isotope dilution mass spectrometry (IDMS)-traceable methods. The reference creatinine was measured using the modified Jaffe method by a certified laboratory and the point-of-care testing was conducted using an i-STAT blood analyzer (i-STAT1, with and without adjustment for the partial pressure of carbon dioxide). AKI was defined and staged using the Kidney Disease: Improving Global Outcomes criteria.

Results: The mean age of children was 2.1 years, and $21.6 \%$ of children were stunted. Mortality was $7.6 \%$ in-hospital. Over the entire range of measured creatinine values $(<0.20 \mathrm{mg} / \mathrm{dL}-8.4 \mathrm{mg} / \mathrm{dL})$, the correlation between the reference creatinine and adjusted and unadjusted point-of-care creatinine was high with $\mathrm{R}^{2}$ values of 0.95 and 0.93 respectively; however, the correlation was significantly lower in children with creatinine values $<1 \mathrm{mg} / \mathrm{dL}$ ( $R^{2}$ of 0.44 between the reference and adjusted and unadjusted i-STAT creatinine). The prevalence of AKI was $45.5 \%$ using the reference creatinine, and 27.1 and $32.3 \%$ using the unadjusted and adjusted point-of-care creatinine values, respectively. There was a step-wise increase in mortality across AKI stages, and all methods were strongly associated with mortality $(p<0.0001$ for all). AKI defined using the reference creatinine measure was the most sensitive to predict mortality with a sensitivity of $85.4 \%$ compared to 70.7 and $63.4 \%$ with the adjusted and unadjusted point-of-care creatinine values, respectively.

Conclusions: Point-of-care assessment of creatinine in lean Ugandan children $<4$ years of age underestimated creatinine and AKI compared to the clinical reference. Additional studies are needed to evaluate other biomarkers of AKI in LMIC to ensure equitable access to AKI diagnostics globally.

\footnotetext{
*Correspondence: conroya@iu.edu

${ }^{2}$ Department of Pediatrics, Ryan White Center for Pediatric Infectious

Disease and Global Health, Indiana University School of Medicine, 1044 W.

Walnut St., Indianapolis, IN 46202, USA

Full list of author information is available at the end of the article
}

(C) The Author(s) 2021. Open Access This article is licensed under a Creative Commons Attribution 4.0 International License, which permits use, sharing, adaptation, distribution and reproduction in any medium or format, as long as you give appropriate credit to the original author(s) and the source, provide a link to the Creative Commons licence, and indicate if changes were made. The images or other third party material in this article are included in the article's Creative Commons licence, unless indicated otherwise in a credit line to the material. If material is not included in the article's Creative Commons licence and your intended use is not permitted by statutory regulation or exceeds the permitted use, you will need to obtain permission directly from the copyright holder. To view a copy of this licence, visit http://creativecommons.org/licenses/by/4.0/. The Creative Commons Public Domain Dedication waiver (http://creativeco mmons.org/publicdomain/zero/1.0/) applies to the data made available in this article, unless otherwise stated in a credit line to the data. 
Keywords: Acute kidney injury, Diagnosis, Point-of-care testing, Sub-Saharan Africa, Prevalence, Mortality, Pediatric, Malaria

\section{Background}

Acute kidney injury (AKI) is an important public health challenge, particularly in low-and middle-income countries (LMIC) where $85 \%$ of the estimated 13.3 million cases per year occur $[1,2]$. AKI is widely recognized as a risk factor for mortality with large multi-site international studies in neonates [3], children [4] and adults [5] all identifying $\mathrm{AKI}$ as an independent risk factor for mortality. LMIC are critically under-represented in global AKI research-particularly sub-Saharan Africa-in part due to limitations in the availability, accessibility and affordability of diagnostic tools [6].

Mortality in AKI in children in sub-Saharan Africa remains unacceptably high at $34 \%$ compared to a global average of $14 \%$ [7]. Failure to recognize AKI can lead to disease progression requiring more aggressive therapies like kidney replacement therapy that are costly and often unavailable in LMIC. Early recognition of children at risk of AKI and the initiation of appropriate supportive care to correct hypovolemia and discontinue the use of nonessential nephrotoxic medications can reduce progression and improve outcomes [8]. Malaria is a significant cause of AKI in sub-Saharan Africa [9-14], and malariaassociated AKI is associated with substantial morbidity and mortality [15-19], increasing the risk of mortality inhospital as well as an increased long-term risk of neurocognitive and behavioral problems in survivors $[18,20]$.

AKI is diagnosed based on increases in serum creatinine (SCr) or decreases in urine output [21]. In practice, AKI diagnosis is often based on changes in $\mathrm{SCr}$ as urine output is challenging to accurately quantify in critically ill populations without catheterization and is further complicated by insufficient nursing care in many LMIC. In LMIC, AKI is primarily a community-acquired condition affecting previously healthy children and young adults on admission to the hospital [22]. Therefore, $\mathrm{SCr}$ is the most useful measure in the initial assessment of AKI in a febrile child presenting with dehydration or volume depletion. To improve awareness and recognition of AKI as an important complication in children in LMIC, clinicians need access to tools to accurately measure kidney function $[6,22]$.

Although children with severe malaria frequently present with multiple severe malaria complications and multi-organ dysfunction [18, 23], AKI is a common complication in children with severe malaria $[17,18]$ and independently predicts mortality [17-19, 23]. Diagnosis of AKI is dependent on the use of an appropriate estimate of baseline $\mathrm{SCr}$ [24] and an accurate measure of SCr. Access to $\mathrm{SCr}$ testing remains a critical barrier in many African health care settings [25], and increased availability of point-of-care devices to measure $\mathrm{SCr}$ across all levels of health care could substantially improve the recognition and management of AKI in resourcelimited settings. The majority of studies assessing performance of point-of-care devices to measure $\mathrm{SCr}$ have been conducted in high-income settings in adult populations [26-28] where SCr levels are substantially higher than pediatric populations. Therefore, there is a need to evaluate point-of-care tests in pediatric populations where small changes in $\mathrm{SCr}$ may constitute AKI.

We evaluated the performance of the i-STAT1 handheld blood analyzer as a point-of-care tool to measure $\mathrm{SCr}$ and define AKI compared to a reference value obtained by a certified clinical laboratory. We present analyses comparing the correlation, bias, and precision of measures over the entire range of $\mathrm{SCr}$ values obtained. Further, as our population of interest is children $<5$ years of age with low estimated baseline $\mathrm{SCr}$ values, we conducted additional analyses focusing on the lower range of $\mathrm{SCr}$ values characteristic of lean pediatric populations. Using the $\mathrm{SCr}$ values from the different test methods, we assessed the prevalence and severity of AKI on admission and evaluated the ability of the different AKI definitions to predict mortality.

\section{Methods}

\section{Study population}

Between 2014 and 2017, 600 children with a clinical definition of severe malaria were enrolled in the study. Children were eligible if they were between 6 months to 4 years of age, had diagnostic evidence of malaria with either a positive rapid diagnostic test for Plasmodium falciparum histidine-rich protein-2 (HRP-2) or direct visualization of parasites by Giemsa microscopy, required hospitalization and met selected criteria for severe malaria (coma, respiratory distress, multiple seizures, severe anemia, or prostration). Exclusion criteria included known chronic illness requiring medical care, history of coma, head trauma, known developmental delay, cerebral palsy or prior hospitalization for malnutrition.

\section{Creatinine testing}

At enrollment, all children had a venous blood draw. The i-STAT System was used to assess a basic metabolic panel 
(CHEM8+ cartridge: SCr, blood urea nitrogen (BUN), glucose, ionized calcium, sodium, potassium, chloride, bicarbonate) and blood gases (CG4 cartridge: $\mathrm{pH}, \mathrm{PCO}_{2}$, $\mathrm{PO}_{2}, \mathrm{TCO}_{2}, \mathrm{HCO}_{3}$, base excess, $\mathrm{sO}_{2}$ ) on lithium heparin whole blood (Abbott Point of Care Inc., Princeton, NJ). Blood was tested immediately upon collection by trained nurses and medical officers following the manufacturer's recommendations. The i-STAT system is designed for in vitro quantification of $\mathrm{SCr}$ in arterial, venous, or capillary whole blood using $95 \mathrm{uL}$ of sample and provides results within two minutes with a reportable range for $\mathrm{SCr}$ of 0.20-20.0 $\mathrm{mg} / \mathrm{dL}$. SCr was measured using an enzymatic assay with amperometric detection on a platinum electrode. As the partial pressure of carbon dioxide $\left(\mathrm{PCO}_{2}\right)$ can affect measurement of SCr by i-STAT, values were adjusted based on the $\mathrm{PCO}_{2}$ values as follows: for $\mathrm{SCr}$ values below $2 \mathrm{mg} / \mathrm{dL}$ and $P C O 2$ values above $40 \mathrm{mmHg}$, $[\mathrm{Cr}]$ corrected $=[\mathrm{Cr}] \mathrm{i}-\mathrm{STAT} \mathrm{X}\left\{1-\left(0.069 \times\left[\left(\mathrm{PCO}_{2}\right.\right.\right.\right.$ -40)/10])\}; and for $\mathrm{SCr}$ values above $2 \mathrm{mg} / \mathrm{dL},[\mathrm{Cr}]$ corrected $=[\mathrm{Cr}] \mathrm{i}$-STAT $\mathrm{X}\left\{1-\left(0.037 \mathrm{X}\left[\left(40-\mathrm{PCO}_{2}\right) / 10\right]\right)\right\}$ [29].

Serum samples were shipped to the United States of America on dry ice and SCr was measured using a Beckman Coulter AU5822 chemistry analyzer using the modified Jaffe colorimetric method (Beckman Coulter, Brea, California) at the Indiana University Pathology Laboratory. The limit of detection of the assay is $0.20 \mathrm{mg} / \mathrm{dL}$, and the coefficient of variation of the assay is $4.1 \%$ at 0.80 $\mathrm{mg} / \mathrm{dL}$ and $2.1 \%$ at $5.5 \mathrm{mg} / \mathrm{dL}$.

Both methods of $\mathrm{SCr}$ measurement were traceable to an isotope dilution mass spectrometry (IDMS) reference method using the U.S. National Institute of Standards and Technology (NIST) Standard Reference material SRM967. Samples below the limit of detection were assigned a value of $0.19 \mathrm{mg} / \mathrm{dL}$.

\section{Defining acute kidney injury}

Acute kidney injury was defined using the Kidney Disease: Improving Global Outcomes (KDIGO) criteria [21] based on a 1.5-fold increase in SCr over the estimated baseline. Staging was as follows: stage 1, 1.5-1.9 fold increase in SCr over baseline; stage 2, 2.0-2.9 fold increase over baseline; stage 3, $\geq 3.0$ fold increase over baseline. Baseline $\mathrm{SCr}$ was estimated using a height-independent approach to back-calculate $\mathrm{SCr}$ using the Pottel age-based equation, where eGFR $=107.3 /(\mathrm{SCr} / \mathrm{Q})$, assuming a normal GFR of $120 \mathrm{~mL} / \mathrm{min}$ per $1.73 \mathrm{~m}^{2}$ (heightindependent), and $\mathrm{Q}=0.0270$ *age +0.2329 [30]. This method was previously validated in Ugandan children and was the most accurate method to estimate baseline $\mathrm{SCr}$ with minimal bias [24]. A single $\mathrm{SCr}$ measure was available on admission, and data on urine output were not collected. Dialysis was not available on-site at the time the study was conducted.

\section{Statistical analysis}

Data were analyzed using STATA v14.0 (StataCorp) and GraphPad Prism v7.03. Differences in $\mathrm{SCr}$ measures by test methodology were evaluated using a number of statistical tests. Concentrations of SCr were compared using Pearson's correlation. The Bland-Altman method [31] was used to measure agreement between the $\mathrm{SCr}$ values obtained by each test approach based on the variance of differences in concentration across the mean of concentration values. Bias was represented by the mean difference between methods of estimating $\mathrm{SCr}$, and precision represents one standard deviation of the bias. Proportional bias is represented by the slope of the regression line of the differences between reference and i-STAT SCr against the average of reference and i-STAT SCr, where a slope of 0 means no proportional bias. To evaluate the relationship between AKI and mortality, we used logistic regression to estimate the odds ratio (OR) adjusting for age, sex, and height-for-age z score. A $p$ value $<0.05$ was considered significant. The ability of AKI to discriminate between children who survived and children who died was assessed using non-parametric receiver operating characteristic (ROC) curve analysis using the method of Delong et al. [32], and presenting the area under the curve.

\section{Role of the funding source}

The funders had no role in the study design, analysis, or decision to publish.

\section{Results}

Of the 600 enrolled in the study, 539 children had paired $\mathrm{SCr}$ measures using the point-of-care i-STAT test and by the reference laboratory and are included in this analysis. The mean (SD) age of the 539 children enrolled in this study was $2.1(0.9)$ years, with $42.9 \%$ of children female. The mean anthropometric $\mathrm{z}$ scores were -1.1 (1.1), -1.1 (1.3), and -0.7 (1.1) for weight-for-age, height-for-age and weight-for-height respectively. Undernutrition was common, with 116 (21.6\%) of children stunted on enrollment. Overall, 11 children were living with HIV-1 (2.1\%), and $21(4.0 \%)$ children had a positive blood culture for bacteremia. Although all children enrolled were diagnosed with severe malaria based on a positive blood smear or a positive rapid diagnostic test for HRP-2, only 368 (68.3\%) of children included in this analysis were smear-positive for malaria. A total of 41 children died during hospitalization (7.6\%). The study flow is shown in Fig. 1. 


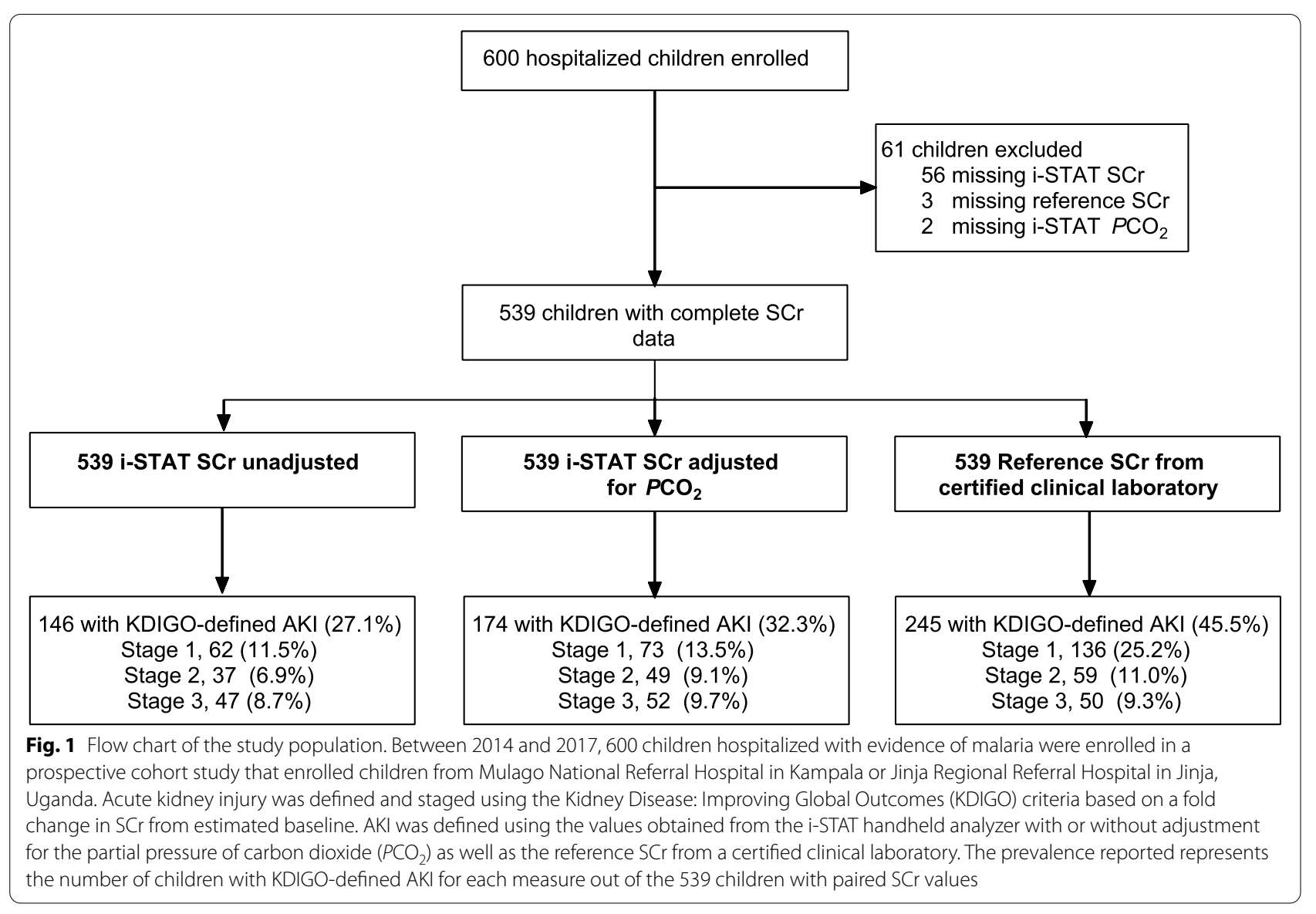

\section{Correlation of i-STAT vs. biochemistry SCr measures}

We compared the paired $\mathrm{SCr}$ measures from i-STAT (adjusted and unadjusted for $P \mathrm{CO}_{2}$ ) to the reference $\mathrm{SCr}$ from a clinical laboratory. The mean (SD) of the reference $\mathrm{SCr}$ value was 0.49 (0.56), and the unadjusted and adjusted i-STAT SCr values were $0.44(0.63)$ and 0.47 (0.60), respectively. The values ranged from 0.19 $\mathrm{mg} / \mathrm{dL}$ as the lowest value across all assays to the highest value of $7.3 \mathrm{mg} / \mathrm{dL}$ for the reference $\mathrm{SCr}, 8.4 \mathrm{mg} / \mathrm{dL}$ for the unadjusted i-STAT SCr, and $7.7 \mathrm{mg} / \mathrm{dL}$ for the adjusted i-STAT SCr. Overall, the correlation between the reference and point-of-care methods was high over the entire range of the assay with $R^{2}$ values of 0.95 and 0.93 for the unadjusted and adjusted $\mathrm{SCr}$ values, respectively (Fig. 2). When the analysis was restricted to children with a SCr measure $<1 \mathrm{mg} / \mathrm{dL}$ by the reference test ( $n=504,94 \%$ of all results), the correlation was significantly lower with an $R^{2}$ value of 0.44 between the reference $\mathrm{SCr}$ and both the unadjusted and adjusted point-of-care SCr measures (Fig. 2).

\section{Agreement between SCr from the clinical reference laboratory and point-of-care i-STAT}

To assess agreement between the point-of-care and clinical reference concentrations of $\mathrm{SCr}$, we used the Bland-Altman method. This graphical tool can present systematic bias between two methods of measurement and identify outliers across the range of the assay (Fig. 3). We conducted the Bland-Altman analysis over the entire range of $\mathrm{SCr}$ measures obtained and also focused on evaluating the bias and precision of the assay at the lower range of the assay $(\mathrm{SCr}<1 \mathrm{mg} / \mathrm{dL})$ where the majority of $\mathrm{SCr}$ measures fell. Compared to the reference value, there was more bias with lower SCr measures by the point-ofcare test with the largest difference observed when the values were not corrected for the $\mathrm{PCO}_{2}$. Proportional bias was assessed by evaluating whether the slope of the regression line presented on the graphs was different from zero. Irrespective of whether i-STAT measures were adjusted or unadjusted, there was significant proportional bias (Fig. 3). Although the estimated baseline $\mathrm{SCr}$ 

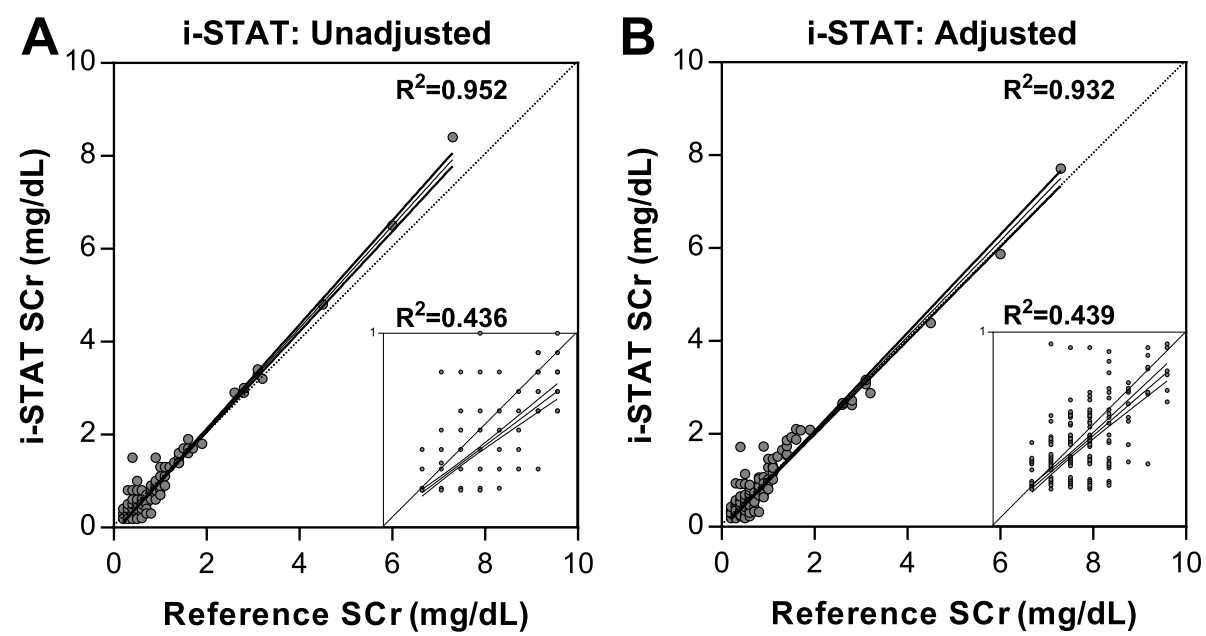

Fig. 2 Correlation between SCr measured by the point-of-care test and the clinical reference. Scatter plot showing the SCr measures by the point-of-care and the reference SCr where (A) is unadjusted i-STAT value and (B) adjusted SCr. The $\mathrm{R}^{2}$ for the correlation is presented on the graph with the regression line and $95 \%$ confidence interval shaded in grey. A separate correlation was performed in children with a reference $\mathrm{SCr}$ value less than $1 \mathrm{mg} / \mathrm{dL}(n=509)$ and presented as an inset in each graph

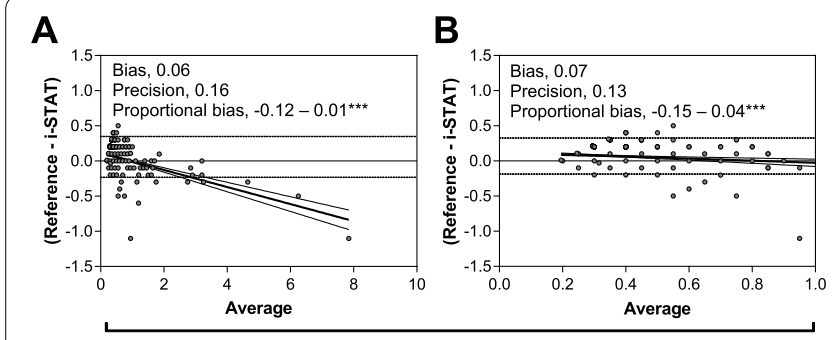

i-STAT: SCr Unadjusted
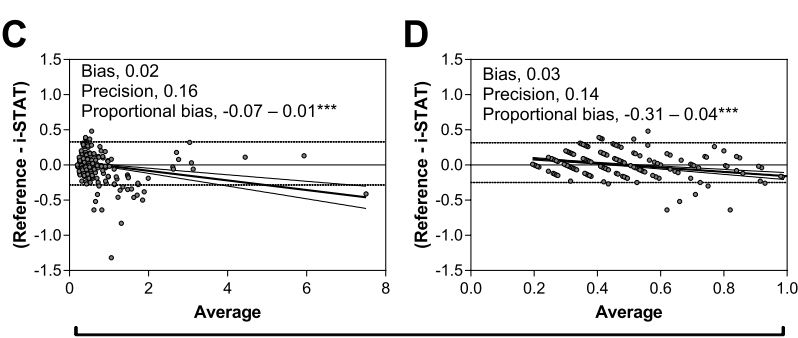

i-STAT: SCr Adjusted

Fig. 3 Bland-Altman analysis comparing the agreement between point-of-care SCr and the clinical reference. A Bland-Altman graph plotting the difference between values on the $y$-axis (Reference- i-STAT) compared to the average value [(Reference $+\mathrm{i}$-STAT)/2] over the range of the assay (A, C) and when the reference SCr measure was $<1 \mathrm{mg} / \mathrm{dL}(\mathbf{B}, \mathbf{D})$. The bias represents the absolute mean difference between the reference and i-STAT $\mathrm{SCr}$ measure, and the precision is one standard deviation of the bias. The horizontal dashed line depicts the $95 \%$ limits of agreement. Proportional bias was evaluated by testing if the slope of the linear regression model of the difference between reference and i-STAT SCr against the average of reference and i-STAT SCr differed from zero. Proportional bias represents the slope (B1) + SE (standard error), and the asterisks indicate whether the slope is statistically different from zero. ${ }^{* * *} p<0.0001$

value varied by age, the mean estimated baseline for the study population was $0.26 \mathrm{mg} / \mathrm{dL}$ (range, $0.22-0.30$ ). The mean and range of $\mathrm{SCr}$ across AKI stages using the reference SCr measure was as follows: stage $1 \mathrm{AKI}$, mean 0.44 $\mathrm{mg} / \mathrm{dL}$ (range: $0.34-0.57 \mathrm{mg} / \mathrm{dL}$ ); stage $2 \mathrm{AKI}$, mean 0.60 $\mathrm{mg} / \mathrm{dL}$ (range: $0.48-0.82 \mathrm{mg} / \mathrm{dL}$ ); stage $3 \mathrm{AKI}$, mean 1.7 $\mathrm{mg} / \mathrm{dL}$ (range: $0.72-7.3 \mathrm{mg} / \mathrm{dL}$ ).

\section{The relationship between $\mathrm{AKI}$ and mortality by $\mathrm{SCr}$ measure}

As AKI is well-recognized as a predictor of mortality, we evaluated the ability of AKI to discriminate between children who survived and children who died as an objective and clinically meaningful outcome (Fig. 4). Using ROC curve analysis to evaluate the ability of the different measures to discriminate between the hospital outcome, all AKI definitions had moderate, and comparable, discriminatory ability with the areas under the curve (AUC) ranging from 0.70-0.72 (Fig. 4). AKI defined using the reference $\mathrm{SCr}$ measure was the most sensitive to predict mortality with a sensitivity of $85.4 \%$ compared to $70.7 \%$ with the adjusted point-of-care $\mathrm{SCr}$ and $63.4 \%$ with the unadjusted point-of-care SCr. When AKI was staged, the AUC for the reference laboratory (0.78) was higher than the AUC from the point-of-care $\mathrm{SCr}(0.72-0.74)$. The unadjusted point-of-care $\mathrm{SCr}$ underestimated Stage 


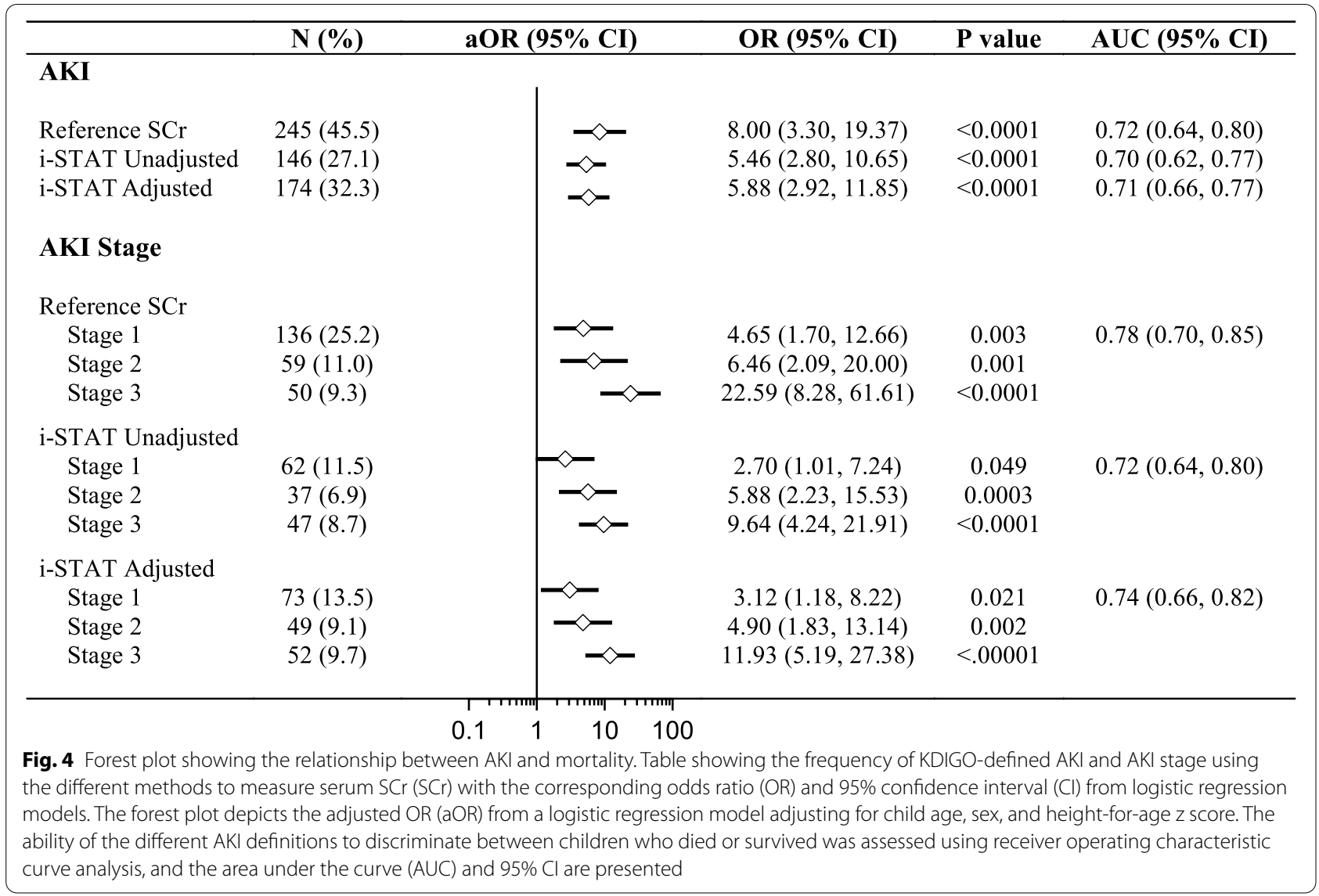

1 and Stage 2 AKI compared to the reference method (Stage 1, 25.2\% (reference) vs. 11.5\% (i-STAT unadjusted); Stage 2, 11.0\% (reference) vs. 6.9\% (adjusted point-of-care $\mathrm{SCr}$ ), which resulted in lower sensitivity to predict mortality (Fig. 4).

By multivariate analysis, AKI remained an independent predictor of mortality following adjustment for child age, sex, and nutritional status (height-for-age z score). These findings were consistent across AKI definitions and AKI stages irrespective of the method to measure SCr (Fig. 4), and there was a step-wise increase in mortality across AKI stages.

\section{Discussion}

AKI is an under-recognized clinical complication associated with significant pediatric mortality globally. In the present study, we evaluated the ability of the i-STAT handheld point-of-care blood analyzer to measure SCr compared to a clinical reference using the modified Jaffe reaction. Compared to the certified clinical laboratory, the point-of-care test measured lower $\mathrm{SCr}$ values even after adjustment for the partial pressure of $\mathrm{CO}_{2}$ that is recognized to affect test performance. While the correlation between the two assays was high over the whole range of reported values $(0.19-8.4 \mathrm{mg} / \mathrm{dL})$, there was only moderate correlation across the range of lower $\mathrm{SCr}$ values typically measured in young children. When AKI was defined based on the unadjusted point-of-care $\mathrm{SCr}$ compared to the clinical reference, 99 (40\%) of AKI episodes were missed (99/245). Although AKI was strongly associated with mortality across all AKI definitions with a step-wise increase in mortality across AKI stages, the relationship between AKI and mortality was strongest in children with $\mathrm{SCr}$ measured by the certified clinical laboratory.

The reference method employed in this study was measuring SCr using the modified Jaffe reaction. Although the modified Jaffe reaction is recognized as traceable to the international standard, it is susceptible to interference through pseudo-chromogens resulting in $\mathrm{SCr}$ overestimation. Enzymatic reactions, like the ones used by the handheld i-STAT device, are generally considered more sensitive and specific than the Jaffe reaction. However, enzymatic $\mathrm{SCr}$ tests are considerably more expensive (estimated at $\$ 2.00$ per test rather than $\$ 0.30)$ than the modified Jaffe reaction [33]. Thus, the enzymatic test is not offered by all laboratories, was not available through the clinical laboratory that performed 
the testing, and is not currently available in Uganda. Therefore, while the reference standard remains an imperfect standard, the modified Jaffe reaction remains the only laboratory method accessible in Uganda.

Although i-STAT SCr correlated strongly with the reference measure across the entire range of the assay, the correlation was only moderate in children with a $\mathrm{SCr}$ value $<1 \mathrm{mg} / \mathrm{dL}$. As this was a relatively young pediatric population and $21.5 \%$ of children were stunted according to WHO standards, the estimated baseline SCr was low across the population, so slight fluctuations in $\mathrm{SCr}$ had a relatively large impact on the estimated prevalence of AKI, reflecting limitations in SCr-based AKI definitions. Correspondingly, the AKI definitions differed in their ability to predict mortality. The unadjusted i-STAT SCr measure had a sensitivity of $63.4 \%$ to predict mortality compared to $85.4 \%$ using the reference method to define AKI. Although the sensitivity of the assay was better when adjusting for the $P \mathrm{CO}_{2}$, the requirement for an additional cartridge to obtain the $P \mathrm{CO}_{2}$ measure makes it considerably more expensive to obtain adjusted values and impractical in a clinical setting.

Although the i-STAT had lower sensitivity to define AKI in this pediatric population, it remained strongly associated with mortality (mortality, 3.8\% in children without i-STAT defined AKI compared to $17.8 \%$ in children with i-STAT defined AKI), and was able to correctly identify $41 / 50(82 \%)$ of children with Stage 3 AKI where mortality was $32.0 \%$. Thus, i-STAT remains a valuable point-of-care tool to identify children with AKI at increased risk of death in settings where laboratory assessment of SCr is unavailable. The i-STAT system would likely have better performance in adult populations where baseline $\mathrm{SCr}$ values are considerably higher, and identifying a $50 \%$ change in $\mathrm{SCr}$ from baseline would be less affected by assay imprecision. Most of the discrepancies in AKI in the present study were in defining Stage 1 AKI, which represented an average increase in $\mathrm{SCr}$ from an estimated baseline from $0.26 \mathrm{mg} / \mathrm{dL}$ to $0.44 \mathrm{mg} /$ dL.

In a global survey published in 2017 to assess the current state of kidney care, only $12 \%$ of countries in Africa reported that they usually have the services to measure $\mathrm{SCr}$ with eGFR reporting at the primary care level, while $39 \%$ reported they never have the services available [25]. Further, when assessing reported methods of $\mathrm{SCr}$ assessment in sub-Saharan Africa, most papers (82\%) do not report whether SCr was measured using IDMS traceable assays, and only 6/80 studies used the more accurate enzymatic method [34]. This highlights the inherent challenges in measuring $\mathrm{SCr}$ across sub-Saharan and the need for substantial development of laboratory capacity in order to expand access to SCr testing. As $\mathrm{SCr}$ is a relatively late marker of $\mathrm{AKI}$, is affected by nutritional status and age, and is logistically and technically challenging to measure, efforts to identify and validate alternative biomarkers of AKI are needed.

Although it is not specific to AKI, blood urea nitrogen (BUN) accumulates when kidney function decreases. In Ugandan children with severe malaria, BUN is strongly correlated with AKI and outperforms serum $\mathrm{SCr}$ in predicting mortality [17]. The prognostic utility of BUN has been demonstrated in over 5000 African children with severe malaria across 11 sites in 9 African countries [35]. BUN is water-soluble and can be monitored non-invasively in saliva (saliva urea nitrogen, SUN) using a semiquantitative lateral flow dipstick. Studies assessing the discriminative ability of dipstick SUN to detect elevated BUN have reported sensitivities ranging from 77-85\% and specificities of $85-88 \%$ [36]. SUN has been tested in several adult populations, including populations in lowresource settings, where SUN had good performance of identifying AKI with areas under the ROC curve $>0.80$ [37-40]. Recent validation in a pediatric population from Sudan found that SUN could be used to identify, screen, and monitor pediatric patients with severe AKI [41].

A handheld point-of-care device that could be employed across all levels of health care would present an opportunity to substantially improve the recognition and management of AKI in resource-limited settings. In order for devices to be useful, they must be able to measure kidney function accurately, affordably, and should be amenable for use in remote tropical settings where heat and humidity can affect test performance [36]. For example, the upper limit of the temperature range for the i-STAT is $30^{\circ} \mathrm{C}$; however, many regions in sub-Saharan Africa have temperatures that exceed $30^{\circ} \mathrm{C}$ during hot seasons. Further, as i-STAT machines are not widely available in sub-Saharan Africa, it can be expensive and logistically challenging to maintain a supply of cartridges and controls that are not expired. Shelf-life is an important consideration when assessing the cost and performance of different platforms, and the ability to operate without a need for electricity in sites where there are frequent interruptions to grid electricity. A recent review assessed the strengths and limitations of existing pointof-care platforms for use in LMIC [36]. All test platforms cost thousands of dollars to purchase the device (range: $\$ 3995-20,000$ USD), and test cartridges or strips cost in the range of \$4-20 USD per test [36]. Without significant reductions in price to increase accessibility, existing point-of-care $\mathrm{SCr}$ tests are not appropriate for routine clinical use in LMIC settings.

While a diagnosis of AKI currently requires a measure of $\mathrm{SCr}$ or assessment of urine output, other measures of impaired kidney function may have utility in identifying 
children with kidney dysfunction in LMIC. Additional studies are needed to evaluate the performance of existing AKI biomarkers (e.g., urine neutrophil gelatinaseassociated lipocalin [42-44], Cystatin C [44-47], SUN [37-40]), as well as next-generation AKI biomarkers [44, $45,48]$ in LMIC settings where the etiology and pathophysiology of AKI may differ from high-income settings. As AKI biomarkers are discovered and validated, it is crucial to consider their utility across all resource settings.

\section{Conclusion}

In this study, we found that the i-STAT measurement of $\mathrm{SCr}$ in a population of lean Ugandan children underestimated SCr compared to a clinical reference measure and led to the under-diagnosis of AKI. AKI was strongly associated with mortality irrespective of test methodology. The development of point-of-care approaches to measure $\mathrm{SCr}$ with good precision at lower $\mathrm{SCr}$ concentrations would be beneficial for pediatric populations. More importantly, there is an urgent need for AKI diagnostics that are temperature stable, affordable, and can be equitably accessed by patients in LMIC.

\begin{abstract}
Abbreviations
AKI: Acute Kidney Injury; AUC: Area under the curve; BUN: Blood urea nitrogen; Cl: Confidence Interval; GFR: Glomerular filtration rate; HIV: Human immunodeficiency virus; KDIGO: Kidney Disease: Improving Global Outcomes; LMIC: Low- and middle-income country; NGAL: Neutrophil gelatinase-associated lipocalin; $\mathrm{OR}$ : Odds ratio; $\mathrm{PCO}_{2}$ : Partial pressure of carbon dioxide; $\mathrm{ROC}$ : Receiver operator characteristic; SCr: Serum creatinine; SUN: Saliva urea nitrogen; WHO: World Health Organization.
\end{abstract}

\section{Acknowledgments}

We thank the children and their parents who participated in this study, the study team for their dedicated effort in treating the children and collecting the data.

\section{Authors' contributions}

$A B, K M$, and JMS participated in the study design, data analysis, and critical review of the manuscript. $\mathrm{RN}, \mathrm{ROO}$, and KC participated in the study design, data collection, and critical review of the manuscript. CCJ participated in the study design, supervision, and critical review of the manuscript. ALC conceived of the study, performed the analysis, and wrote the first draft of the manuscript. All authors reviewed and approved the submitted manuscript.

\section{Funding}

This work was supported by the National Institute of Neurological Disorders and Stroke (grants R01NS055349 to CCJ) and the Fogarty International Center (D43 NS078280 to CCJ), and a Ralph W. and Grace M. Showalter research award to ALC.

\section{Availability of data and materials}

The datasets used and/or analyzed during the current study are available from the corresponding author on reasonable request.

\section{Declarations}

\section{Ethics approval and consent to participate}

Written informed consent was obtained from the parents or legal guardians of all study participants. Ethical approval was granted by the Institutional Review Boards at Makerere University School of Medicine (Ref: 2013-141, date approved: September 23, 2014), the University of Minnesota (Ref: 1309M42501, date approved: September 23, 2013) and subsequently moved to Indiana University (Ref: 1412213778, date approved: January 20, 2015). The Uganda National Council for Science and Technology approved the study (Ref: HS1522, date approved: May 12, 2013).

\section{Consent for publication}

Not applicable.

\section{Competing interests}

The authors report no competing interests.

\section{Author details}

${ }^{1}$ Child Health and Development Centre, Makerere University College of Health Sciences, Kampala, Uganda. ${ }^{2}$ Department of Pediatrics, Ryan White Center for Pediatric Infectious Disease and Global Health, Indiana University School of Medicine, 1044 W. Walnut St., Indianapolis, IN 46202, USA. ${ }^{3}$ Department of Paediatrics and Child Health, Makerere University College of Health Sciences, Kampala, Uganda. ${ }^{4}$ Department of Epidemiology and Biostatistics, Makerere University School of Public Health, Kampala, Uganda.

Received: 16 October 2020 Accepted: 22 October 2021

Published online: 06 November 2021

\section{References}

1. Mehta RL, Cerda J, Burdmann EA, Tonelli M, Garcia-Garcia G, Jha V, et al. International Society of Nephrology's 0by25 initiative for acute kidney injury (zero preventable deaths by 2025): a human rights case for nephrology. Lancet. 2015;385(9987):2616-43.

2. Susantitaphong P, Cruz DN, Cerda J, Abulfaraj M, Alqahtani F, Koulouridis I, et al. World incidence of AKI: a meta-analysis. Clin J Am Soc Nephrol. 2013;8(9):1482-93.

3. Jetton JG, Boohaker LJ, Sethi SK, Wazir S, Rohatgi S, Soranno DE, et al. Incidence and outcomes of neonatal acute kidney injury (AWAKEN): a multicentre, multinational, observational cohort study. Lancet Child Adolesc Health. 2017;1(3):184-94.

4. Kaddourah A, Basu RK, Bagshaw SM, Goldstein SL, Investigators A. Epidemiology of acute kidney injury in critically III children and young adults. N Engl J Med. 2017;376(1):11-20.

5. Hoste EA, Bagshaw SM, Bellomo R, Cely CM, Colman R, Cruz DN, et al. Epidemiology of acute kidney injury in critically ill patients: the multinational AKI-EPI study. Intensive Care Med. 2015;41(8):1411-23.

6. Cerda J, Mohan S, Garcia-Garcia G, Jha V, Samavedam S, Gowrishankar S, et al. Acute kidney injury recognition in low- and middle-income countries. Kidney Int Rep. 2017;2(4):530-43.

7. Olowu WA, Niang A, Osafo C, Ashuntantang G, Arogundade FA, Porter J, et al. Outcomes of acute kidney injury in children and adults in Sub-Saharan Africa: a systematic review. Lancet Glob Health. 2016;4(4):e242-50.

8. Goldstein SL, Chawla L, Ronco C, Kellum JA. Renal recovery. Crit Care. 2014;18(1):301.

9. Ademola AD, Asinobi AO, Ekpe-Adewuyi E, Ayede Al, Ajayi SO, Raji YR, et al. Acute kidney injury among paediatric emergency room admissions in a tertiary hospital in South West Nigeria: a cohort study. Clin Kidney J. 2019;12(4):521-6.

10. Esezobor CI, Ladapo TA, Osinaike B, Lesi FE. Paediatric acute kidney injury in a tertiary hospital in Nigeria: prevalence, causes and mortality rate. PLoS One. 2012;7(12):e51229.

11. Esezobor Cl, Ladapo TA, Lesi FE. Clinical profile and hospital outcome of children with severe acute kidney injury in a developing country. J Trop Pediatr. 2015;61(1):54-60.

12. Imani PD, Odiit A, Hingorani SR, Weiss NS, Eddy AA. Acute kidney injury and its association with in-hospital mortality among children with acute infections. Pediatr Nephrol. 2013;28(11):2199-206.

13. Diarrassouba G, Adonis-Koffy L, Niamien E, Yaokreh JB, Coulibaly PA. Acute peritoneal dialysis in African pediatric area experience of pediatric nephrology unit of Yopougon University Hospital (Abidjan, Cote d'Ivoire). Blood Purif. 2015;39(1-3):141-4.

14. Olowu WA, Adelusola KA. Pediatric acute renal failure in southwestern Nigeria. Kidney Int. 2004;66(4):1541-8. 
15. Waller D, Krishna S, Crawley J, Miller K, Nosten F, Chapman D, et al. Clinical features and outcome of severe malaria in Gambian children. Clin Infect Dis. 1995;21(3):577-87.

16. Jallow M, Casals-Pascual C, Ackerman $H$, Walther B, Walther M, Pinder M, et al. Clinical features of severe malaria associated with death: a 13-year observational study in the Gambia. PLoS One. 2012;7(9):e45645.

17. Conroy AL, Hawkes M, Elphinstone RE, Morgan C, Hermann L, Barker $\mathrm{KR}$, et al. Acute kidney injury is common in pediatric severe malaria and is associated with increased mortality. Open Forum Infect Dis. 2016;3(2):ofw046

18. Conroy AL, Opoka RO, Bangirana P, Idro R, Ssenkusu JM, Datta D, et al. Acute kidney injury is associated with impaired cognition and chronic kidney disease in a prospective cohort of children with severe malaria. BMC Med. 2019;17(1):98.

19. Sypniewska P, Duda JF, Locatelli I, Althaus CR, Althaus F, Genton B. Clinical and laboratory predictors of death in African children with features of severe malaria: a systematic review and meta-analysis. BMC Med. 2017;15(1):147.

20. Hickson MR, Conroy AL, Bangirana P, Opoka RO, Idro R, Ssenkusu JM, et al. Acute kidney injury in Ugandan children with severe malaria is associated with long-term behavioral problems. PLoS One. 2019;14(12):e0226405.

21. KDIGO. KDIGO clinical practice guideline for acute kidney injury. Kidney Int Suppl. 2012;2(1):1-138.

22. Lewington AJ, Cerda J, Mehta RL. Raising awareness of acute kidney injury: a global perspective of a silent killer. Kidney Int. 2013;84(3):457-67.

23. Plewes K, Turner GDH, Dondorp AM. Pathophysiology, clinical presentation, and treatment of coma and acute kidney injury complicating falciparum malaria. Curr Opin Infect Dis. 2018;31(1):69-77.

24. Batte A, Starr MC, Schwaderer AL, Opoka RO, Namazzi R, Phelps Nishiguchi ES, et al. Methods to estimate baseline SCr and define acute kidney injury in lean Ugandan children with severe malaria: a prospective cohort study. BMC Nephrol. 2020;21(1):417.

25. Bello AK, Levin A, Tonelli M, Okpechi IG, Feehally J, Harris D, et al. Assessment of global kidney health care status. JAMA. 2017;317(18):1864-81.

26. Kosack CS, de Kieviet W, Bayrak K, Milovic A, Page AL. Evaluation of the Nova StatSensor(R) Xpress(TM) Creatinine point-of-care handheld analyzer. PLoS One. 2015;10(4):e0122433.

27. Blanchard IE, Kozicky R, Dalgarno D, Simms J, Goulder S, Williamson TS, et al. Community paramedic point of care testing: validity and usability of two commercially available devices. BMC Emerg Med. 2019;19(1):30

28. Corbett M, Duarte A, Llewellyn A, Altunkaya J, Harden M, Harris M, et al. Point-of-care SCr tests to assess kidney function for outpatients requiring contrast-enhanced CT imaging: systematic reviews and economic evaluation. Health Technol Assess. 2020;24(39):1-248.

29. Abbott Point of Care Inc.: Creatinine crea. In. Edited by 714183-01W A; 2016.

30. Pottel H, Hoste L, Martens F. A simple height-independent equation for estimating glomerular filtration rate in children. Pediatr Nephrol. 2012:27.

31. Altman DG, Bland JM. Measurement in medicine: the analysis of method comparison studies. Statistician. 1983;32(3):307.

32. DeLong ER, DeLong DM, Clarke-Pearson DL. Comparing the areas unde two or more correlated receiver operating characteristic curves: a nonparametric approach. Biometrics. 1988:44(3):837-45.

33. Schmidt RL, Straseski JA, Raphael KL, Adams AH, Lehman CM. A risk assessment of the jaffe vs enzymatic method for creatinine measurement in an outpatient population. PLoS One. 2015;10(11):e0143205.

34. Fabian J, George JA, Etheredge HR, van Deventer M, Kalyesubula R, Wade AN, et al. Methods and reporting of kidney function: a systematic review of studies from sub-Saharan Africa. Clin Kidney J. 2019;12(6):778-87.
35. von Seidlein L, Olaosebikan R, Hendriksen IC, Lee SJ, Adedoyin OT, Agbenyega T, et al. Predicting the clinical outcome of severe falciparum malaria in African children: findings from a large randomized trial. Clin Infect Dis. 2012;54(8):1080-90.

36. Raimann JG, Riella MC, Levin NW. International Society of Nephrology's 0 by 25 initiative (zero preventable deaths from acute kidney injury by 2025): focus on diagnosis of acute kidney injury in low-income countries. Clin Kidney J. 2018;11(1):12-9.

37. Calice-Silva V, Vieira MA, Raimann JG, Carter M, Callegari J, Levin NW, et al. Saliva urea nitrogen dipstick - a novel bedside diagnostic tool for acute kidney injury. Clin Nephrol. 2014;82(6):358-66.

38. Evans R, Calice-Silva V, Raimann JG, Hemmila U, Craik A, Mtekateka M, et al. Diagnostic performance of a saliva urea nitrogen dipstick to detect kidney disease in Malawi. Kidney Int Rep. 2017;2(2):219-27.

39. Raimann JG, Calice-Silva V, Thijssen S, Nerbass FB, Vieira MA, Dabel P, et al. Saliva urea nitrogen continuously reflects blood urea nitrogen after acute kidney injury diagnosis and management: longitudinal observational data from a collaborative, international, prospective, multicenter study. Blood Purif. 2016;42(1):64-72.

40. Calice-Silva V, Sacomboio E, Raimann JG, Evans R, Dos Santos Sebastiao C, Tchivango AT, et al. Diagnostic performance of salivary urea nitrogen dipstick to detect and monitor acute kidney disease in patients with malaria. Malar J. 2018;17(1):477.

41. Hussein RH, Calice-Silva V, Evans R, Levin NW, Ellidir RA, Ali EM, et al. Diagnosis of acute kidney injury in children hospitalized in a SubSaharan African unit by saliva urea nitrogen dipstick test. Blood Purif. 2020:49(1-2):185-96.

42. Devarajan P. Neutrophil gelatinase-associated lipocalin: a promising biomarker for human acute kidney injury. Biomark Med. 2010;4(2):265-80.

43. Ning M, Mao X, Niu Y, Tang B, Shen H. Usefulness and limitations of neutrophil gelatinase-associated lipocalin in the assessment of kidney diseases. J Lab Precision Med. 2018;3(1).

44. Dai X, Zeng Z, Fu C, Zhang S, Cai Y, Chen Z. Diagnostic value of neutrophil gelatinase-associated lipocalin, cystatin C, and soluble triggering receptor expressed on myeloid cells-1 in critically ill patients with sepsis-associated acute kidney injury. Crit Care. 2015;19(1):223.

45. Schley G, Koberle C, Manuilova E, Rutz S, Forster C, Weyand M, et al. Comparison of plasma and urine biomarker performance in acute kidney injury. PLoS One. 2015;10(12):e0145042.

46. Ataei N, Bazargani B, Ameli S, Madani A, Javadilarijani F, Moghtaderi M, et al. Early detection of acute kidney injury by serum cystatin C in critically ill children. Pediatr Nephrol. 2014;29(1):133-8.

47. Dharnidharka VR, Kwon C, Stevens G. Serum cystatin C is superior to serum $\mathrm{SCr}$ as a marker of kidney function: a meta-analysis. Am J Kidney Dis. 2002;40(2):221-6.

48. Westhoff JH, Tonshoff B, Waldherr S, Poschl J, Teufel U, Westhoff TH, et al. Urinary tissue inhibitor of metalloproteinase-2 (TIMP-2) * insulin-like growth factor-binding protein 7 (IGFBP7) predicts adverse outcome in pediatric acute kidney injury. PLoS One. 2015;10(11):e0143628.

\section{Publisher's Note}

Springer Nature remains neutral with regard to jurisdictional claims in published maps and institutional affiliations.

Ready to submit your research? Choose BMC and benefit from:

- fast, convenient online submission

- thorough peer review by experienced researchers in your field

- rapid publication on acceptance

- support for research data, including large and complex data types

- gold Open Access which fosters wider collaboration and increased citations

- maximum visibility for your research: over 100M website views per year

At BMC, research is always in progress.

Learn more biomedcentral.com/submissions 